\title{
Ultra-hypofractionated whole breast adjuvant radiotherapy in the real-world setting: single experience with 271 elderly/frail patients treated with 3D and IMRT technique
}

\author{
Maria Alessia Zerella ${ }^{1}$. Samantha Dicuonzo ${ }^{1}$. Samuele Frassoni ${ }^{2} \cdot$ Mattia Zaffaroni $^{1}$ (1) . \\ Marianna Alessandra Gerardi ${ }^{1}$. Anna Morra ${ }^{1}$. Damaris Patricia Rojas ${ }^{1}$ - Simona Arculeo ${ }^{1}$. \\ Luca Bergamaschi $^{1,5}$. Cristiana Fodor ${ }^{1}$. Francesca Emiro ${ }^{3}$. Consiglia Piccolo ${ }^{3}$. Vincenzo Bagnardi ${ }^{2}$. \\ Federica Cattani ${ }^{3}$. Viviana Galimberti ${ }^{4} \cdot$ Paolo Veronesi $^{4,5} \cdot$ Roberto Orecchia $^{6} \cdot$ Maria Cristina Leonardi $^{1}$. \\ Barbara Alicja Jereczek-Fossa ${ }^{1,5}$
}

Received: 17 December 2021 / Accepted: 26 December 2021 / Published online: 6 January 2022

(c) The Author(s), under exclusive licence to Springer-Verlag GmbH Germany, part of Springer Nature 2022

\begin{abstract}
Purpose The purpose of the study was to evaluate the toxicity, local control, overall and disease-free survival of elderly breast cancer (BC) patients treated with adjuvant once-weekly ultra-hypofractionated radiotherapy (RT) either with intensitymodulated RT (IMRT) or 3D conformal RT (3DCRT).

Methods From July 2011 to July 2018, BC patients receiving 5.7 Gy once a week for 5 weeks to the whole breast after breast-conserving surgery were considered for the study. Inclusion criteria were: T1-T3 invasive BC, no or limited axillary involvement, age $\geq 65$ years or women with commuting difficulties or disabling diseases.

Results A total of 271 patients were included in the study. Median age was 76 (46-86) years. Most of BC were T1 (77\%), while the remaining were T2 $(22.2 \%)$ and T3 $(0.4 \%)$. Axillary status was negative in $68.3 \%$ of the patients. The only severe acute toxicity (G3) at the end of RT was erythema (0.4\%), registered in the 3DCRT group; no G3 edema or epitheliolysis was recorded. With 18 months of median follow-up, severe early-late toxicity (G3) was reported in terms of fibrosis and breast retraction, both with an incidence of 1.4\%, mostly in the 3DCRT group. Oncological outcomes at a median follow-up of 2.9 years reported 249/271 (91.9\%) patients alive and free from any event and 5 (1.8\%) isolated locoregional recurrences. At 3 years, disease-free survival and overall survival were $94.9 \%$ and $97.8 \%$, respectively. Breast volume $>500 \mathrm{~cm}^{3}$ was reported as predictive for moderate-severe ( $\geq \mathrm{G} 2)$ acute toxicity.

Conclusions Weekly ultra-hypofractionated whole breast RT seems feasible and effective. Toxicity was mild, local control was acceptable, and overall survival was $97.8 \%$ at 3 years. Rates of severe toxicity were reduced with the IMRT technique.
\end{abstract}

Keywords Once-weekly ultra-hypofractionated radiotherapy · Whole breast adjuvant radiotherapy · IMRT · 3DCRT ·

Breast cancer

The affiliation of author Consiglia Piccolo refers to the time of data collection.

M. A. Zerella and S. Dicuonzo are co-first authors.

M. C. Leonardi and B. A. Jereczek-Fossa are co-last authors.

Mattia Zaffaroni

mattia.zaffaroni@ieo.it

1 Division of Radiation Oncology, European Institute of Oncology, IEO IRCCS, via Ripamonti, 435, 20141 Milan, Italy

2 Department of Statistics and Quantitative Methods, University of Milan-Bicocca, Milan, Italy

\section{Abbreviations}

3DCRT 3D conformal RT

AIRO Italian Association of Radiotherapy and Clinical Oncology

3 Unit of Medical Physics, European Institute of Oncology, IEO IRCCS, Milan, Italy

4 Division of Breast Surgery, European Institute of Oncology, IEO IRCCS, Milan, Italy

5 Department of Oncology and Hemato-Oncology, University of Milan, Milan, Italy

6 Scientific Direction, European Institute of Oncology, IEO IRCCS, Milan, Italy 


$\begin{array}{ll}\text { BC } & \text { Breast cancer } \\ \mathrm{cm}^{3} & \text { Cubic centimeters } \\ \text { CT } & \text { Computed tomography } \\ \text { CTCAE } & \text { Common Terminology Criteria for } \\ & \text { Adverse Events } \\ \text { CTV } & \text { Clinical target volume } \\ \text { DFS } & \text { Disease-free survival } \\ \text { EORTC } & \text { European Organization for Research and } \\ & \text { Treatment of Cancer } \\ \text { EPIs } & \text { Electronic portal images } \\ \text { IMRT } & \text { Intensity-modulated RT } \\ \text { LENT-SOMA } & \text { Late Effects Normal Tissue Task Force } \\ & \text { Subjective, Objective, Management, and } \\ \text { MaxCBD } & \text { Analytic scale } \\ \text { MaxPTVD } & \text { Maximum contralateral breast dose } \\ \text { MeanHD } & \text { Maximum dose } \\ \text { MeanHLD } & \text { Mean heart dose } \\ \text { MeanPTVD } & \text { Mean homolateral lung dose } \\ \text { MVCT } & \text { Mean dose } \\ \text { OARs } & \text { Megavoltage CT } \\ \text { OS } & \text { Organs at risk } \\ \text { PTV } & \text { Overall survival } \\ \text { RT } & \text { Planning target volume } \\ \text { RTOG } & \text { Radiotherapy } \\ & \text { Radiation Therapy Oncology Group }\end{array}$

\section{Introduction}

Postoperative radiation therapy (RT) after conservative breast surgery is well known to reduce the risk of local recurrence resulting in a survival benefit, regardless of the age (Early Breast Cancer Trialists' Collaborative Group (EBCTCG) et al. 2011), but the absolute benefit on survival is limited in elderly patients as this is more influenced by prior comorbidities.

To date, few conclusive data are available on the treatment of choice for early-stage breast cancer (BC) in elderly patients. Notwithstanding the presence of biologically more favorable prognostic factors with respect to younger patients, older women are at high risk of presenting with $\mathrm{BC}$ when it has already reached a late stage, mostly because of poor BC awareness (Diab et al. 2000; Linsell et al. 2008).

In addition, women older than 70 years tend to be excluded from most large-scale clinical trials (Wildiers et al. 2007), and this category is frequently associated with noncompliance factors, as functional limitation, travel distance or comorbidities could lead to under-treatment (Donato et al. 2003).

Recently, results from FAST-Forward and FAST, two large randomized controlled trials testing five-fraction regimens over 5 weeks or 1 week for adjuvant whole breast radiotherapy, have been published (FAST Trialists group et al. 2011; Murray Brunt et al. 2020; Brunt et al. 2020). The FAST-Forward randomized trial (Murray Brunt et al. 2020) ( $n=4096$; median age $=61$ years $)$ showed that ultrahypofractionation (5 fractions) results in non-inferior local control rates and similar adverse event profile when compared to $40 \mathrm{~Gy}$ in 15 fractions over 3 weeks. The smaller FAST trial (FAST Trialists group et al. 2011; Brunt et al. 2020) randomized 915 women aged $>50$ years and affected by early $\mathrm{BC}$ to receive $50 \mathrm{~Gy}$ in 25 fractions over 5 weeks or two hypofractionated schedules of 30/28.5 Gy in 5 fractions of $6 / 5.7$ Gy once weekly over 5 weeks after breastconserving surgery. At a 9.9-year median follow-up, no differences were shown between 28.5 and $50 \mathrm{~Gy}$ in terms of any moderated/marked physician-scored breast adverse events and local recurrence rates were overall low and similar between arms (overall 11 ipsilateral BC events and 96 deaths), although the trial was not designed to demonstrate efficacy for local control.

At the European Institute of Oncology (IEO), about 700 early breast cancer patients a year are treated with adjuvant RT; many of them live far from Milan, and some have important disability or social/clinical challenges making long therapies unacceptable. For these selected patients, although evidences on five fractions in breast cancer irradiation are still growing, 'real-life data' might provide additional insights with respect to randomized controlled trials (Rodin et al. 2021).

In 2011, based on the encouraging first results coming from FAST trial (FAST Trialists group et al. 2011), adjuvant whole breast radiotherapy treatment in five fractions was implemented in our facility.

The aim of this study is to retrospectively review our experience in terms of toxicity, local control, and overall and disease-free survival of elderly/frail early-stage BC patients treated with adjuvant once-weekly ultra-hypofractionated RT, either with intensity-modulated RT (IMRT) or 3D conformal RT (3DCRT).

\section{Patients and methods}

\section{Patients' selection and study design}

Data of patients treated with adjuvant once-weekly ultrahypofractionated RT at the European Institute of Oncology IRCCS (IEO) in Milan, Italy between July 2011 and July 2018 were retrospectively analyzed.

Women with age $\geq 65$ or commuting difficulties or disabling diseases who underwent breast-conserving surgery for early-stage BC, with no limit regarding systemic therapy regimens were included. The study was part of a research project entitled "Adjuvant radiation treatments with intensity-modulated radiotherapy and/or hypofractionated 
schedules for breast cancer" which was notified to the Ethical Committee of the European Institute of Oncology (26 May 2016, Milan, Italy). All patients gave written informed consent for the treatment and anonymous use of their data for educational and research purposes.

\section{End points}

The primary end point was the assessment of acute (within 6 months) and early-late toxicities; secondary endpoints included local control (in terms of local and locoregional recurrences), overall survival (OS) and disease-free survival (DFS). Additionally, a comparison between 3DCRT and IMRT techniques was performed with regard to the aforementioned end points.

\section{Treatment protocol}

All patients underwent computed tomography (CT) simulation with axial CT images with a slice thickness of $2.5 \mathrm{~mm}$ acquired in the supine position.

Target volumes and organs at risk (OARs) were contoured using the Eclipse (Varian) planning system or, since its subsequent implementation in our facility, the RayStation (RaySearch) planning system.

The clinical target volume (CTV) includes the whole palpable breast tissue visualized by CT, without boost to the tumor bed. It is limited anteriorly within $5 \mathrm{~mm}$ from the skin and posteriorly to the anterior surface of the pectoralis muscle, excluding chest wall and lung. Contouring was performed according to national guidelines and the breast cancer atlas of the Italian Association of Radiotherapy and Clinical Oncology (AIRO) (AIRO 2013). To generate the planning target volume (PTV), a $5 \mathrm{~mm}$ margin was added to CTV.

Breast volume was measured in cubic centimeters $\left(\mathrm{cm}^{3}\right)$; a "small" volume was assigned to breast volumes $<500$ $\mathrm{cm}^{3}$, a "medium" volume was assigned to breast volumes between 500 and $1000 \mathrm{~cm}^{3}$, and a "large" volume was assigned to breast volumes $>1000 \mathrm{~cm}^{3}$.

The prescription dose was $28.50 \mathrm{~Gy}$ in five fractions (5.70 Gy per fraction) once a week for 5 weeks.

Contoured OARs included lungs, contralateral breast, heart, left anterior descending artery, spinal cord, liver and stomach.

The RT treatment was delivered using either a 3DCRT with two tangential wedged fields (Trilogy, Varian) or the direct modality of the TomoTherapy Hi-Art System (Tomotherapy Inc., Madison, WI).

Daily setup verification was image guided using electronic portal images (EPIs) of the tangential beams for 3DCRT and a megavoltage CT (MVCT) before each tomotherapy fraction.
The objective of treatment planning was to ensure that $\geq 95 \%$ of the breast target volume (PTV) was covered by $\geq 95 \%$ of the prescribed dose.

Dosimetric data for target coverage and for the specified OARs were collected as follows:

With regard to PTV:

- Mean dose (MeanPTVD).

- Maximum dose (MaxPTVD). With regard to OARs:

- Mean heart dose (MeanHD).

- Maximum contralateral breast dose (MaxCBD).

- Mean homolateral lung dose (MeanHLD).

\section{Clinical and toxicity evaluation}

The length of follow-up was calculated from the end of RT to the last record in the clinical charts. Patients were followed at least by one of the multidisciplinary BC teams, composed of surgeons, medical oncologists and radiation oncologists.

Acute toxicity was assessed using the Radiation Therapy Oncology Group (RTOG) and European Organization for Research and Treatment of Cancer (EORTC) acute scales (Hjermstad et al. 2011). The reported toxicity represents the maximal recorded acute toxicity within 6 months after RT.

Early-late toxicity represents the maximal chronic toxicity during follow-up after 6 months after treatment completion, and it was assessed using the Late Effects Normal Tissue Task Force Subjective, Objective, Management, and Analytic scale (LENT-SOMA) (1995); cosmesis was assessed at last follow-up, using Harvard criteria (Harris et al. 1979).

Acute and early-late G2 and G3 toxicity events were considered as "moderate" and "severe" toxicities, respectively.

\section{Statistical considerations}

Continuous data are reported as median and ranges. Categorical data are reported as counts and percentages.

The association between patients' characteristics and moderate-severe acute or chronic skin toxicity was evaluated in univariate analyses using Chi-square test, Fisher's exact test or Cochran-Armitage trend test when appropriate.

Difference of both acute and late skin toxicity and dosimetric variables between techniques were evaluated with Wilcoxon signed rank test for continuous variable and Chisquare test or Fisher's exact test for categorical variables.

Weighted kappa statistic was used to evaluate the agreement among physician-assessed and patient-assessed cosmesis.

Recurrence was defined as local if occurring within the ipsilateral breast, locoregional if occurred in ipsilateral 
axillary, supraclavicular, or internal mammary lymph nodes, and distant if occurred elsewhere.

Disease-free survival (DFS) included all the first unfavorable events (local, locoregional and distant recurrences), other primaries and deaths. For overall survival (OS), death from any cause was considered.

The OS and DFS were estimated using the Kaplan-Meier method. Univariate Cox proportional hazard regression models were used to assess the association between demographic, disease and treatment characteristics and the development of event. Poisson exact model was performed when no events were observed in one of the covariate categories.

A different subgroup analysis was performed to investigate OS and tumor outcome in a category of patients selected according to the FAST Trial (FAST Trialists group et al. 2011; Brunt et al. 2020) inclusion criteria (age $\geq 50$ years, invasive carcinoma, breast-conserving surgery, tumor size $<3 \mathrm{~cm}$ and negative axillary node status). A $p$ value $<0.05$ was considered statistically significant for all analyses.

All analyses were performed with the statistical software SAS 9.4 (SAS Institute, Cary, NC).

\section{Results}

\section{Patients and treatments characteristics}

Two hundred and seventy-one patients have been included in this study.

The baseline characteristics of patients, and tumor and treatment characteristics are listed in Table 1.

The median age was 76 (46-86) years. Most of BC were pT1 (77\%), while the remaining were T2 $(22.2 \%)$ and T3 $(0.4 \%)$. Axillary status was negative in $68.3 \%$, minimally involved in $14.4 \%$ (pN1) and not assessed in $17.3 \%$ of the cases (Nx). Negative surgical margins were found in $90.6 \%$ of patients.

Tumors were mainly ductal carcinomas (75.6\%), unifocals $(75.4 \%)$, of intermediate grade (54.7\%), with absent/ reduced/focal in situ component (82.1\%), and absent/focal vascular invasion $(96.3 \%)$.

The mainly represented $\mathrm{BC}$ molecular subtype in our cohort was luminal A $(48.8 \%)$.

Most of the women received only hormonal therapy $(84.1 \%)$ and no other systemic therapies.

The RT schedule was delivered either with 3CDRT for $133(49.1 \%)$ patients or with IMRT for $138(50.9 \%)$ patients.

Breast volume measurement resulted in 97 (35.8\%), $132(48.7 \%)$ and 42 patients (15.5\%) having "small", "medium" and "large" volume, respectively.

\section{Toxicity evaluation}

All patients were evaluable for acute toxicity; maximum acute toxicity within 6 months after RT was severe erythema in $0.4 \%$ of patients, while no severe edema or desquamation occurred. Considering any acute toxicity, it was mostly of grade $1(56.5 \%)$.

Acute severe toxicities for the 3DCRT group were registered in $1 / 133(0.8 \%)$ patients; no severe toxicities were reported for the IMRT group (Table 2).

Among the initial 271 patients, 141 (52\%) had also an RT visit after 6 months with a median follow-up of $18.1(6.0-55.2)$ months.

For all the 141 patients with a follow-up visit after 6 months, any severe early-late toxicity was reported in $2.1 \%$, in terms of fibrosis and breast retraction (Table S1).

Among the 141 patients with early-late toxicity assessment, 69 and 72 were treated with 3DCRT and IMRT, respectively. The median follow-up between the two groups was different with $23.4(6.0-55.2)$ months for the 3D group and 13.0 (6.0-38.0) months for the IMRT group. Details are reported in Table S1.

At univariate analysis, a predictive factor for moderate-severe toxicity resulted in breast volume $(\mathrm{P}$ value $<0.001$ ) for acute toxicity, while none was correlated with early-late toxicity (Table 3 ).

Breast volume was confirmed statistically significant $(P$ value $<0.001)$ in toxicity prediction also adjusting for technique (3DCRT vs. IMRT) in a multivariate analysis with moderate-severe acute skin toxicity as dependent variable.

Cosmetic evaluation was available for 116 (42.8\%) patients with a median follow-up of $17.9(6.2-55.2)$ months. Excellent, good, fair and poor outcome was recorded for 31 (26.7\%), $69(59.5 \%), 15(12.9 \%)$ and $1(0.9 \%)$ patients according to patient evaluation, respectively, and for $29(25 \%), 76(65.5 \%)$, $10(8.6 \%), 1(0.9 \%)$ according to physician evaluation, respectively.

Among the 116 patients with cosmetic evaluation, 55/116 were treated with 3DCRT and 61/116 were treated with IMRT. In the 3DCRT group, at a median follow-up of 23.7 (6.2-55.2) months-fair and poor cosmesis was reported by $10 / 55$ and $1 / 55$ patients.

In the IMRT group, at a median follow-up of 12.6 (6.3-37.2) months - 5/61 patients reported fair cosmesis, and no poor cosmesis was registered.

The percent of concordance between physician and patient was $73.3 \%$, with a moderate agreement: kappa $(95 \% \mathrm{CI})$ was $0.53(0.39-0.67)$. 
Table 1 Patient demographics and disease characteristics

\begin{tabular}{|c|c|c|}
\hline Variable & Level & Overall $(N=271)$ \\
\hline Age, median (min-max) & & $76(46-86)$ \\
\hline \multirow[t]{3}{*}{ Age, $N(\%)$} & $<70$ & $10(3.7)$ \\
\hline & $70-79$ & $215(79.3)$ \\
\hline & $80+$ & $46(17.0)$ \\
\hline \multirow[t]{2}{*}{ Concomitant pathologies, $N(\%)$} & No & $43(15.9)$ \\
\hline & Yes & $228(84.1)$ \\
\hline \multirow[t]{2}{*}{ Laterality, $N(\%)$} & Left & $119(43.9)$ \\
\hline & Right & $152(56.1)$ \\
\hline \multirow[t]{4}{*}{ Axillary surgery, $N(\%)$} & Quadrantectomy & $50(18.5)$ \\
\hline & Quadrantectomy + SNB & $195(72.2)$ \\
\hline & $\begin{array}{l}\text { Quadrantectomy + AD with/without } \\
\text { SNB }\end{array}$ & $25(9.3)$ \\
\hline & Missing & 1 \\
\hline \multirow[t]{5}{*}{ T Stage, $N(\%)$} & pTis & $1(0.4)$ \\
\hline & pT1 & $208(77.0)$ \\
\hline & pT2 & $60(22.2)$ \\
\hline & pT3 & $1(0.4)$ \\
\hline & Missing & 1 \\
\hline \multirow[t]{3}{*}{ N stage, $N(\%)$} & $\mathrm{pNx}$ & $47(17.3)$ \\
\hline & pNO & $185(68.3)$ \\
\hline & $\mathrm{pN} 1$ & $39(14.4)$ \\
\hline \multirow[t]{3}{*}{ Histological type, $N(\%)$} & Ductal & 205 (75.6) \\
\hline & Lobular/mixed & $48(17.7)$ \\
\hline & Other & $18(6.6)$ \\
\hline \multirow[t]{4}{*}{ Tumor grade, $N(\%)$} & 1 & $38(14.2)$ \\
\hline & 2 & $146(54.7)$ \\
\hline & 3 & $83(31.1)$ \\
\hline & Missing & 4 \\
\hline \multirow[t]{3}{*}{ In situ component, $N(\%)$} & Absent/reduced/focal & $220(82.1)$ \\
\hline & Present/extended/prevalent & $48(17.9)$ \\
\hline & Missing & 3 \\
\hline \multirow[t]{4}{*}{ Focality, $N(\%)$} & Unifocality & $202(75.4)$ \\
\hline & Bifocality & $43(16.0)$ \\
\hline & Multifocality & $23(8.6)$ \\
\hline & Missing & 3 \\
\hline \multirow[t]{3}{*}{ Vascular invasion, $N(\%)$} & Absent/focal & $257(96.3)$ \\
\hline & Present/extended & $10(3.7)$ \\
\hline & Missing & 4 \\
\hline \multirow[t]{3}{*}{ Surgical margin, $N(\%)$} & Negative & $242(90.6)$ \\
\hline & Proximal & $25(9.4)$ \\
\hline & Missing & 4 \\
\hline \multirow[t]{2}{*}{$\mathrm{ER}, N(\%)$} & Negative & $27(10.0)$ \\
\hline & Positive & $244(90.0)$ \\
\hline \multirow[t]{2}{*}{$\mathrm{PgR}, N(\%)$} & Negative & $53(19.6)$ \\
\hline & Positive & $218(80.4)$ \\
\hline \multirow[t]{3}{*}{$\mathrm{Ki} 67, N(\%)$} & $<20$ & $132(50.4)$ \\
\hline & $\geq 20$ & $130(49.6)$ \\
\hline & Missing & 9 \\
\hline \multirow[t]{3}{*}{ HER $2, N(\%)$} & Negative & $250(94.0)$ \\
\hline & Positive & $16(6.0)$ \\
\hline & Unknown $\diamond$ & 5 \\
\hline
\end{tabular}


Table 1 (continued)

\begin{tabular}{lll}
\hline Variable & Level & Overall $(N=271)$ \\
\hline Biological Classification, $N(\%)$ & Luminal A & $126(48.8)$ \\
& Luminal B (Ki67 $\geq 20 \%)$ & $95(36.8)$ \\
& Luminal B (Her2 positive) & $11(4.3)$ \\
& HER2 positive & $5(1.9)$ \\
& Triple negative & $21(8.1)$ \\
Adjuvant therapy, $N(\%)$ & Unknown II & 13 \\
Hormonal therapy, $N(\%)$ & None & $14(5.2)$ \\
& HT only & $228(84.1)$ \\
CT with/without HT & $29(10.7)$ \\
Technique, $N(\%)$ & Letrozole & $72(30.7)$ \\
Breast volume $(\mathrm{CTVm}), N(\%)$ & Tamoxifen & $29(12.4)$ \\
& Anastrozole & $125(53.4)$ \\
& Exemestane & $8(3.4)$ \\
& 3 D technique & $133(49.1)$ \\
& IMRT technique & $138(50.9)$ \\
& Small $\left(<500 \mathrm{~cm}^{3}\right)$ & $97(35.8)$ \\
& Medium $\left(500-1000 \mathrm{~cm}^{3}\right)$ & $132(48.7)$ \\
& Large $\left(>1000 \mathrm{~cm}^{3}\right)$ & $42(15.5)$
\end{tabular}

$\diamond$ Five patients with Her2 $=2+$ and FISH test not executed

II Four patients with Her2 $=2+$ and FISH test not executed, eight patients with Ki 67 missing, and one patient with both Her2 $=2+$ and FISH test not executed and Ki 67 missing

Table 2 Acute skin toxicity (at the end of RT)

\begin{tabular}{|c|c|c|c|c|}
\hline \multirow[t]{2}{*}{ Acute skin toxicity } & Overall $(\mathrm{N}=271)$ & $\begin{array}{l}\text { Patients treated } \\
\text { with 3D technique } \\
(\mathrm{N}=133)\end{array}$ & $\begin{array}{l}\text { Patients treated with } \\
\text { IMRT technique } \\
(\mathrm{N}=138)\end{array}$ & $P$ value $*$ \\
\hline & \multicolumn{4}{|l|}{$N(\% \mathrm{col})$} \\
\hline \multicolumn{5}{|l|}{ Erythema } \\
\hline G0 & $79(29.2)$ & $52(39.1)$ & $27(19.6)$ & \multirow[t]{4}{*}{0.19} \\
\hline G1 & $172(63.5)$ & $74(55.6)$ & $98(71.0)$ & \\
\hline $\mathrm{G} 2$ & $19(7.0)$ & $6(4.5)$ & $13(9.4)$ & \\
\hline G3 & $1(0.4)$ & $1(0.8)$ & $0(0.0)$ & \\
\hline \multicolumn{5}{|l|}{ Edema } \\
\hline G0 & $244(90.0)$ & $118(88.7)$ & $126(91.3)$ & \multirow[t]{2}{*}{0.48} \\
\hline $\mathrm{G} 2$ & $27(10.0)$ & $15(11.3)$ & $12(8.7)$ & \\
\hline \multicolumn{5}{|l|}{ Epitheliolysis } \\
\hline G0 & $255(94.1)$ & $123(92.5)$ & $132(95.7)$ & \multirow[t]{3}{*}{1.00} \\
\hline G1 & $12(4.4)$ & $8(6.0)$ & $4(2.9)$ & \\
\hline $\mathrm{G} 2$ & $4(1.5)$ & $2(1.5)$ & $2(1.4)$ & \\
\hline \multicolumn{5}{|c|}{ Any acute skin toxicity } \\
\hline G0 & $75(27.7)$ & $50(37.6)$ & $25(18.1)$ & \multirow[t]{4}{*}{0.71} \\
\hline G1 & $153(56.5)$ & $63(47.4)$ & $90(65.2)$ & \\
\hline $\mathrm{G} 2$ & $42(15.5)$ & $19(14.3)$ & $23(16.7)$ & \\
\hline G3 & $1(0.4)$ & $1(0.8)$ & $0(0.0)$ & \\
\hline
\end{tabular}

*Outcome: G2/G3 vs G0/G1. Chi-square test or Fisher's exact test when appropriate 
Table 3 Predictive factors for moderate-severe acute and chronic skin toxicity (any acute/early-late skin toxicity $\geq$ G2): univariate analysis

\begin{tabular}{|c|c|c|c|c|c|c|c|}
\hline \multirow[t]{2}{*}{ Variable } & \multirow[t]{2}{*}{ Level } & \multirow{2}{*}{$\begin{array}{l}\text { Moderate-severe } \\
\text { acute skin toxicity/ } \\
\text { Tot } \\
N(\%)\end{array}$} & \multicolumn{2}{|l|}{ Univariate analysis } & \multirow{2}{*}{$\begin{array}{l}\text { Moderate-severe } \\
\text { early-late skin } \\
\text { toxicity/Tot } \\
N(\%)\end{array}$} & \multicolumn{2}{|l|}{ Univariate analysis } \\
\hline & & & OR $(95 \% \mathrm{CI})$ & $P$ value* & & OR $(95 \% \mathrm{CI})$ & $P$ value* \\
\hline Total & & 43/271 (15.9) & - & - & $35 / 141(24.8)$ & - & - \\
\hline \multirow[t]{2}{*}{ Age $\square$} & $<76$ & 17/137 (12.4) & Ref & 0.12 & $17 / 74(23.0)$ & Ref & 0.59 \\
\hline & $\geq 76$ & 26/134 (19.4) & $1.70(0.88-3.30)$ & & 18/67 (26.9) & $1.23(0.57-2.65)$ & \\
\hline \multirow{2}{*}{$\begin{array}{l}\text { Concomitant } \\
\text { pathologies }\end{array}$} & No & $6 / 43(14.0)$ & Ref & 0.71 & $3 / 15(20.0)$ & Ref & 0.76 \\
\hline & Yes & $37 / 228(16.2)$ & $1.20(0.47-3.03)$ & & $32 / 126(25.4)$ & $1.36(0.36-5.13)$ & \\
\hline \multirow[t]{2}{*}{ Laterality } & Left & $14 / 119(11.8)$ & Ref & 0.10 & $14 / 61(23.0)$ & Ref & 0.65 \\
\hline & Right & $29 / 152(19.1)$ & $1.77(0.89-3.52)$ & & $21 / 80(26.3)$ & $1.20(0.55-2.60)$ & \\
\hline \multirow[t]{2}{*}{ Axillary surgery II } & Quadrantectomy & $7 / 50(14.0)$ & Ref & 0.68 & $6 / 23(26.1)$ & Ref & 0.90 \\
\hline & $\begin{array}{l}\text { Quadrantec- } \\
\text { tomy + SNB/AD }\end{array}$ & $36 / 220(16.4)$ & $1.20(0.50-2.88)$ & & 29/117 (24.8) & $0.93(0.34-2.59)$ & \\
\hline \multirow[t]{2}{*}{$\mathrm{T}$ stage $\mathbb{I}$} & pTis/pT1 & $30 / 209$ (14.4) & Ref & 0.19 & $27 / 112(24.1)$ & Ref & 0.63 \\
\hline & $\mathrm{pT} 2 / \mathrm{pT} 3$ & $13 / 61(21.3)$ & $1.62(0.78-3.34)$ & & $8 / 28(28.6)$ & $1.26(0.50-3.18)$ & \\
\hline \multirow[t]{3}{*}{ Adjuvant therapy } & None & $1 / 14(7.1)$ & Ref & 0.56 & 2/7 (28.6) & Ref & 1.00 \\
\hline & HT only & 40/228 (17.5) & $2.77(0.35-21.7)$ & & 29/119 (24.4) & $0.81(0.15-4.38)$ & \\
\hline & $\begin{array}{l}\text { CT with/without } \\
\text { HT }\end{array}$ & $2 / 29(6.9)$ & $0.96(0.08-11.6)$ & & $4 / 15(26.7)$ & $0.91(0.12-6.72)$ & \\
\hline \multirow[t]{2}{*}{ Technique } & 3D technique & 20/133 (15.0) & Ref & 0.71 & 18/69 (26.1) & Ref & 0.73 \\
\hline & IMRT technique & 23/138 (16.7) & $1.13(0.59-2.17)$ & & $17 / 72(23.6)$ & $0.88(0.41-1.88)$ & \\
\hline \multirow[t]{2}{*}{ MeanPTVD II } & $\leq 100$ & $39 / 231(16.9)$ & Ref & 0.30 & 28/117 (23.9) & Ref & 0.51 \\
\hline & $>100$ & $4 / 39(10.3)$ & $0.56(0.19-1.67)$ & & $7 / 23(30.4)$ & $1.39(0.52-3.72)$ & \\
\hline \multirow[t]{2}{*}{ MaxPTVD } & $\leq 105$ & 9/45 (20.0) & Ref & 0.41 & $7 / 26(26.9)$ & Ref & 0.78 \\
\hline & $>105$ & $34 / 226(15.0)$ & $0.71(0.31-1.60)$ & & 28/115 (24.4) & $0.87(0.33-2.29)$ & \\
\hline \multirow{3}{*}{$\begin{array}{l}\text { Breast volume } \\
(\mathrm{CTVm})\end{array}$} & Small $\left(<500 \mathrm{~cm}^{3}\right)$ & $6 / 97(6.2)$ & Ref & $<0.001 * *$ & $13 / 51(25.5)$ & Ref & $0.93 * *$ \\
\hline & $\begin{array}{l}\text { Medium }(500- \\
\left.1000 \mathrm{~cm}^{3}\right)\end{array}$ & 25/132 (18.9) & 3.54 (1.39-9.02) & & $16 / 66(24.2)$ & $0.94(0.40-2.18)$ & \\
\hline & Large $\left(>1000 \mathrm{~cm}^{3}\right)$ & $12 / 42(28.6)$ & 6.07 (2.10-17.6) & & $6 / 24(25.0)$ & $0.97(0.32-2.98)$ & \\
\hline
\end{tabular}

$\square$ Median value; If 1 missing. * Chi-square test or Fisher's exact test when appropriate; ** Cochran-Armitage trend test for ordinal variables

\section{Clinical outcome}

All 271 patients were evaluable for tumor control and survival analysis. Median follow-up for the whole cohort was 2.92 years $(0.10-7.01)$.

At the time of the analysis, 249/271 (91.9\%) patients were alive and free from any event; $11 / 271$ (4.1\%) patients were alive but experienced some previous event; $1 / 271$ $(0.4 \%)$ patient was dead and experienced a previous event (distant recurrence); 10/271 (3.7\%) patients died as first event.

There was a total of five $(1.8 \%)$ isolated locoregional recurrences: four involved the breast and one the axillary lymph nodes. Three patients $(1.1 \%)$ were found to have distant recurrence and one patient $(0.4 \%)$ developed both locoregional and distant recurrence. Three women (1.1\%) experienced a second cancer in other sites.

Three years OS was 97.8\% (94.5-99.1) (Fig. 1a), and 3 years DFS was $94.9 \%$ (90.5-97.3) (Fig. 1b).
At univariate analysis, significant predictive factors for the development of an event were not found (Table S2).

A total of $172 / 271$ patients matched the FAST Trial (FAST Trialists group et al. 2011; Brunt et al. 2020) inclusion criteria (patients with age $\geq 50$, pathologic tumor size $<3 \mathrm{~cm}$ and axillary node negative); in this subgroup 3 years OS was 99.4 (95.8-99.9) (Fig. 2a) and 3 years DFS was 97.6 (92.3-99.3) (Fig. 2b).

\section{Dosimetric variables}

The median MeanPTVD was 100.0 (97.0-102.0) and the median MaxPTVD was 106.4 (102.2-111.5). The median MeanHD, MaxCBD and MeanHLD was 0.50 (0.13-2.00), $1.00(0.30-27.40)$ and $2.80(0.20-5.64)$, respectively.

Distribution of dosimetric variables between levels of technique are illustrated in Table 4. 

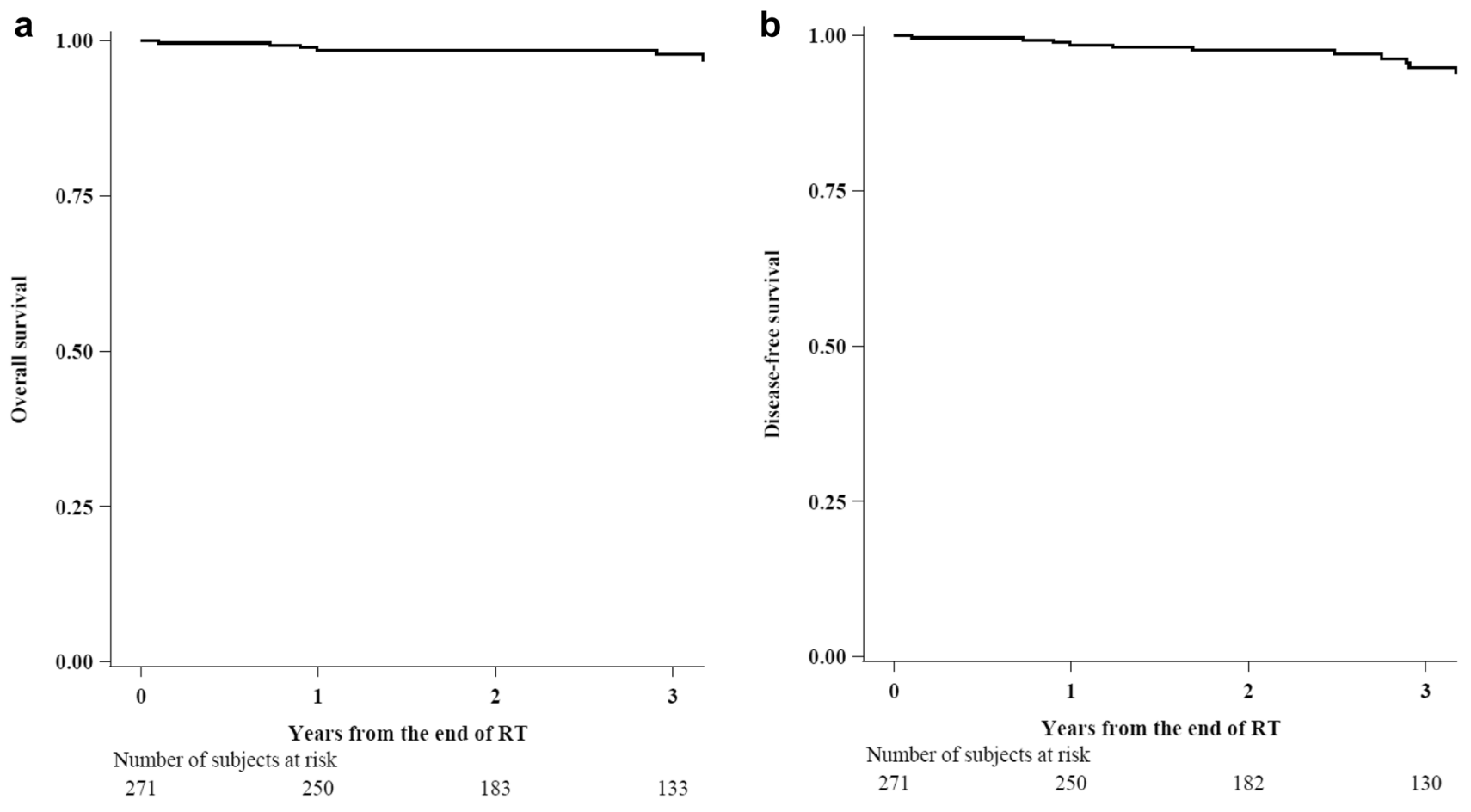

Fig. 1 Overall survival (a) and disease-free survival (b) on the whole cohort $(N=271)$ (follow-up in years (median, min-max): 2.92, 0.10-7.01)
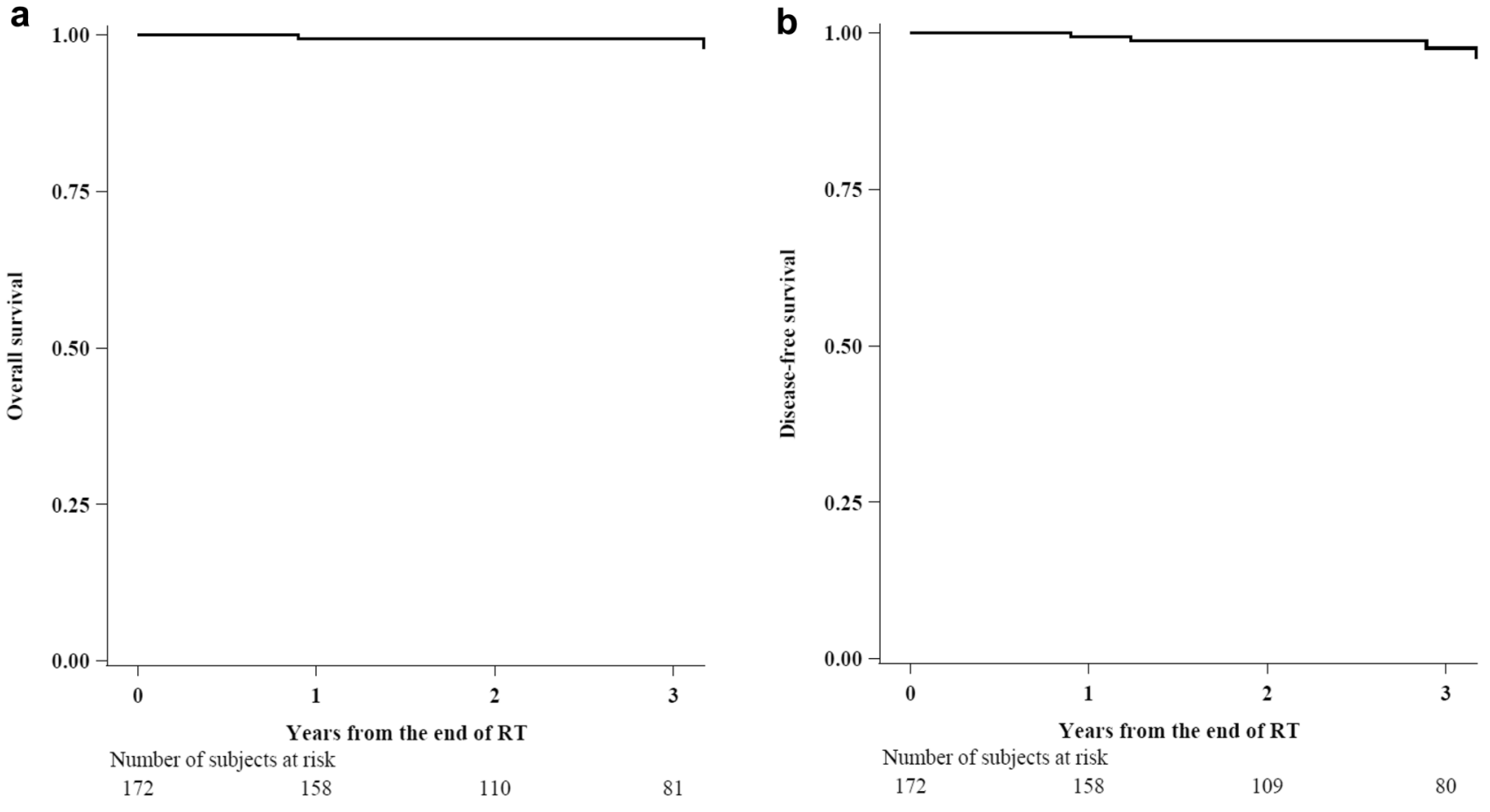

Fig. 2 Overall survival (a) and disease-free survival (b) on a subgroup analysis: patients with age $\geq 50$ and pathologic tumor size $<3 \mathrm{~cm}$ and negative axillary node $(N=172)$ (follow-up in years (median, min-max): $2.76,0.61-6.64$ ) 
Table 4 Distribution of dosimetric variables between the levels of the technique $(N=271)$

\begin{tabular}{lclc}
\hline Variable & 3D technique $(N=133)$ & IMRT technique $(N=138)$ & $P$ value $\mathbb{I}$ \\
\hline MeanPTVD, median (min-max) $\S$ & $100.0(97.0-102.0)$ & $100.0(99.6-101.5)$ & 0.005 \\
MaxPTVD, median (min-max) & $106.3(103.1-108.5)$ & $106.4(102.2-111.5)$ & 0.88 \\
MeanHD, median (min-max)* & $0.56(0.23-1.87)$ & $0.40(0.13-2.00)$ & $<0.001$ \\
MaxCBD, median (min-max) $*$ & $1.10(0.33-27.40)$ & $0.90(0.30-6.80)$ & $<0.001$ \\
MeanHLD, median (min-max) & $2.50(0.20-5.10)$ & $3.14(1.20-5.64)$ & $<0.001$ \\
\hline
\end{tabular}

${ }^{\S}$ One missing; * five missing; * three missing

"Wilcoxon signed rank test for continuous variable

\section{Discussion}

Our study, which includes 271 elderly/frail patients, is one of biggest "real-life" series of ultra-hypofractionation in early $\mathrm{BC}$ and reports encouraging local control and toxicity profile.

In this subset of patients, a multifactorial assessment is necessary to identify the optimal therapeutic strategy, considering that no data are available to categorize a subset of patients in which RT can certainly be excluded (Truong et al. 2006). The alternative of accelerated ultra-hypofractionation RT regimens suits better with quality of life and patient's wishes, as supported by randomized prospective trials that show hypofractionation is not inferior to conventional fractionation in selected patients with early-stage BC (Ortholan et al. 2005; Owen et al. 2006; START Trialists' Group et al. 2008; Whelan et al. 2010; FAST Trialists group et al. 2011; Smith et al. 2011; Brunt et al. 2020).

To our knowledge, this is the first study using both the 3D and the IMRT technique in this field, showing that rates of severe toxicity were slightly reduced with IMRT.

The additional strengths of our study include the confirmation of the safety profile of the RT schedule administered, tested in the FAST randomized trial, and its demonstrated reproducibility in a real-life scenario that better represents the unselected population normally encountered in the everyday clinical practice.

Previous results from studies using once-weekly fractionation for breast cancer are summarized in Table 5 .

Considering moderate-severe acute toxicity at the end of RT, both erythema, edema and epitheliolysis rate did not exceed $10 \%$, in agreement with previous studies (Ortholan et al. 2005; Rovea et al. 2015; Bonzano et al. 2019). This data represents a better result compared to other group findings (Dragun et al. 2013; Sanz et al. 2018; Reboucas et al. 2019), although Dragun et al. and Reboucas et al. rated toxicity with a different scale (CTCAE version 3.0). Furthermore, in our report only one G3 erythema was recorded, confirming severe acute toxicity was negligible/minor.

Importantly, our results are comparable with FAST trial (FAST Trialists group et al. 2011; Brunt et al. 2020). Although in the British trial the clinical assessment of acute skin toxicity was not available for all patients, the collected data demonstrated grade $\geq \mathrm{G} 2$ reactions were less common in both five-fraction test groups as compared to the standard arm (50 Gy: 46.4\%, 30 Gy: 14.4\%, 28.5 Gy: 10.4\%).

Breast size resulted as an independent predictive risk factor for moderate-severe acute toxicity. Goldsmith et al. (2011) reported that large- or heavy-breasted women are more likely than others to suffer change in breast size and shape 2 years after RT; other studies found that large breast volume was correlated with increased probability of acute skin toxicity (Dragun et al. 2013; Ciammella et al. 2014). Our study confirms this data in the setting of early skin reactions, according to the hypothesis that dose inhomogeneity and consequents hotspots are more common in treatment plans of larger breast volumes (Kraus-Tiefenbacher et al. 2012).

Moderate-severe early-late toxicity, fibrosis and breast retraction were mostly recorded (12\% and $9.9 \%$ respectively), in line with hypofractionated whole breast schedules available in literature (START Trialists' Group et al. 2008; Whelan et al. 2010).

Considering any early-late toxicity, Grade 1 and Grade 2 were recorded in $60.3 \%$ and $22.7 \%$ of patients, similarly to Sanz et al. (2018); on the other hand, our data are surprisingly higher with respect to Rovea et al.'s (2015) (no G1 and 6.5\% G2) and Bonzano et al.'s (2019) series (10\% $\mathrm{G} 1$ and $4 \% \mathrm{G} 2$ ), but consideration must be given to the fact that Rovea scored toxicity according to CTCAE version 4.0, while we used LENT-SOMA, and that Bonzano evaluated sub-cutaneous tissue toxicity 20 months after treatment, while in the current report early-late toxicity represents the maximal recorded chronic toxicity during follow-up. Additionally, our investigation reported any Grade 3 early-late toxicity in $2.1 \%$ of patients, a favorable data compared with other literature-reported rates, ranging from $4.3 \%$ (Rovea et al. 2015) to 9\% (Sanz et al. 2018).

Although in the FAST trial early-late toxicity was evaluated through breast appearance on photographic assessments, therefore not directly comparable, our results seem to be encouraging ( $24.8 \%$ of patients with any early-late toxicity $\geq \mathrm{G} 2$ ) and similar to FAST that showed a 2 years of mild/marked adverse effect in the breast in $24 \%$ for 
Table 5 Comparison of acute/late toxicities and oncological outcomes between the current study and different previous studies

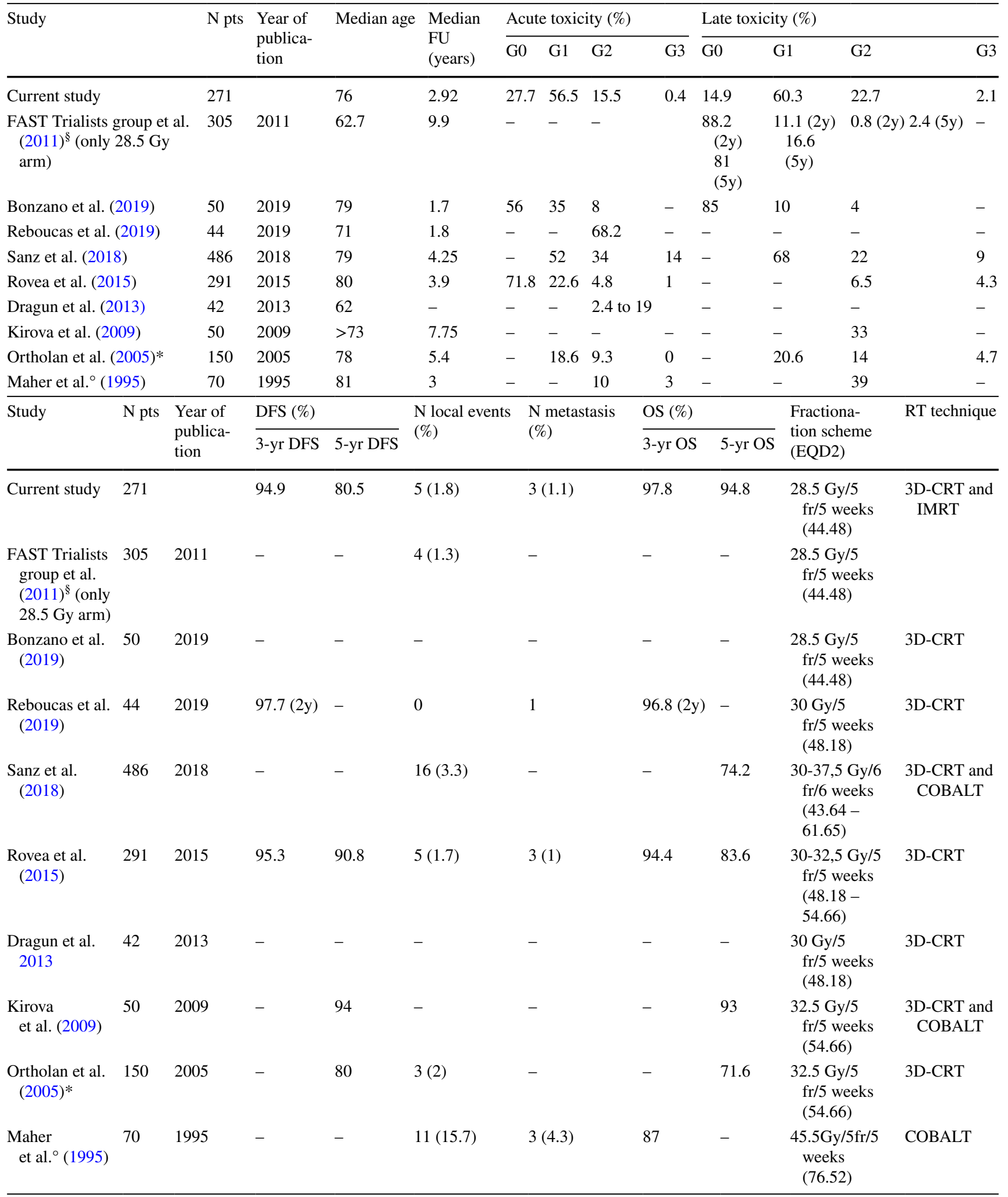

$\S_{\text {Toxicity data from photographs }}$

${ }^{\circ}$ No surgery

$* 28.5 \%$ of the patients performed mastectomy

3D-CRT = 3D conformal RT; DFS = disease-free survival; EQD2 = equivalent dose delivered in 2 Gy/fractions; IMRT =intensity-modulated 
Table 5 (continued)

RT; OS = overall survival; $\mathbf{R T}=$ radiotherapy

28.5 Gy, mostly in terms of breast shrinkage or induration (FAST Trialists group et al. 2011). Interestingly, in the recent study reporting 10-year results of FAST, 2-year photographs were re-evaluated along with the 5-year photographs, yielding a lower number of patients with moderate/marked changes in breast appearance at 2 years (for 28.5 Gy group $11.9 \%$ in the updated analysis vs. $24 \%$ in the initial analysis); 5 years mild/marked adverse effect in the breast in the 28.5 Gy group was 19\% (Brunt et al. 2020).

Consequently, a longer follow-up in our cohort could be useful for a comparative analysis.

It should be noted that early-late toxicity was available for $52 \%$ of patients, since most of them continued their follow-up with breast surgeons. Although it is a limit of the present study, we notice that patients with toxicity come back to the follow-up visits more frequently when compared to the patients without any toxicity; since they did not return, supposedly, they did not exhibit any worse toxicities, improving the general results.

A total of 5/271 patients developed local recurrence (in breast) or regional recurrence (regional lymph nodes), for a locoregional recurrence rate of $1.8 \%$. Moreover, only two $(1.2 \%)$ patients in the sub-analysis according to FAST-inclusion criteria had a local recurrence. This data is similar to that reported in previous studies with the same or similar treatment schedule (Table 5) even though with relatively short follow-up.

When focusing on patients' characteristics, we found that all the five patients but one experiencing local/locoregional recurrences were classified as luminal B Her2 positive; the only Luminal A patient voluntarily discontinued hormonal therapy after 12 months, as did one of the four luminal B Her2-positive patients after 7 months because of joint pain. In addition, one of the local recurrences occurred in the only pT3 in our cohort of patients.

Notably, the two local recurrences among patients selected according to FAST trial inclusion criteria were luminal B Her2 positive; one of them was affected by a grade 3 tumor, with extended vascular invasion and no chemotherapy administered because of patient desire. These observations can partially explain an increased risk of recurrence.

Besides, when compared with Rovea et al. (2015), in which follow-up was slightly longer (46.5 months for Rovea vs 35.04) with a total number of patients (291 in Rovea study vs 271) similar to our report, the locoregional recurrences and the 3-year DFS rate were $5(1.7 \%)$ and $95.3 \%$ (95\% CI, 91.4-97.2) for Rovea and 5 (1.9\%) and 94.9\% (90.5-97.3) for the current report.
Another interesting issue derived from the randomized trial PRIME II (Kunkler et al. 2015), in which older, lowrisk, T1-T2 up to $3 \mathrm{~cm}$, node-negative women with invasive $\mathrm{BC}$, after breast-conserving surgery and while receiving adjuvant endocrine treatment, were randomly assigned to receive whole breast irradiation or no further treatment.

After a median follow-up of 5 years, ipsilateral breast tumor recurrence was $1.3 \%$ in women assigned to whole breast RT, which is similar to our results, and $4.1 \%$ in those assigned to no R; the relapse rate omitting RT has been considered sufficiently low enough to be practice changing for the authors of the trial.

Nevertheless, no international consensus exists on what level of local recurrence in this population would be acceptable if RT were omitted, and their findings advise caution when considering omission of RT for hormone receptor-poor tumors.

Moreover, in the current study we have compared the 3DCRT technique and the IMRT technique in terms of acute and early-late toxicity and dosimetric variables. Although when focusing on acute and early-late toxicity the different technique does not seem to have strongly affected the results, we observed that in the acute toxicity setting the only recorded G3 symptom (erythema) occurred in a 3D-treated patient. Similarly, three of the four G3-recorded events in the early-late toxicity setting (fibrosis and breast retraction) and the only poor cosmetic result occurred in 3DCRT-treated patients.

Hence, our results support the finding that IMRT reduces the occurrence and the severity of acute toxicity compared with a conventional technique, consequently improving patients' quality of life (Freedman et al. 2006; Pignol et al. 2008).

Moreover our data confirm that, comparing the dosimetric variables of two techniques, IMRT spares contralateral breast and heart, independently from the laterality of the tumor; if compared with 3DCRT, slightly higher doses are given with IMRT to the homolateral lung, but always complainant with the constraints and to reduce the incidence of side effects.

The absence of a control group, the retrospective nature of the study and the short follow-up represent the main limitations of the present work.

Recently a five-fraction schedule over just 1 week is being evaluated in the UK FAST-Forward trial (Murray Brunt et al. 2020). The study demonstrated the non-inferiority for two ultra-hypofractionated regimens in terms of local control, at a median follow-up of 71.5 months. Although acute toxicity was reduced with ultra-hypofractionation, early-late toxicity 
rate and poor cosmesis are associated with the higher dose regimens of 27 Gy over 1 week, and the relative risk for any moderate and marked early-late effects result increased over time.

In conclusion, FAST-Forward represents the next generation of hypofractionation trials from the renowned group at the Institute of Cancer Research in the UK; longer follow-up is necessary to evaluate the long-term safety of this regimen, also in consideration of emerging new possibilities in earlystage low-risk breast cancer, as accelerated partial breast irradiation (APBI) and the omission of RT (Kunkler et al. 2015; Correa et al. 2017).

\section{Conclusion}

In our experience, weekly ultra-hypofractionated whole breast RT seems feasible and effective, representing a valuable alternative to long RT schedules or no treatment for patients at low risk of relapse. Local control and OS were acceptable; toxicity was mild and the reduction of total treatment time led to high patients' satisfaction and compliance (Ippolito et al. 2019).

In particular, IMRT has shown a trend toward achieving the goal of reducing severe acute and late radiation toxicity, a relevant issue for this category of patients. Moreover, ultra-hypofractionation for $\mathrm{BC}$ could be an additional option in the light of the current COVID-19 pandemic, optimizing health-care resource allocation and reducing patients' accesses to the hospital.

Moving from the ideal world of randomized controlled trials to the real-world setting, studies that better reflect the true situation of the patients are increasingly important to confirm the efficacy and safety of the treatment in daily routine and in turn improve clinical practice. In this regard, our results in a real-life series are comparable with randomized FAST trial, confirming the effectiveness of the treatment under investigation.

Supplementary Information The online version contains supplementary material available at https://doi.org/10.1007/s00432-021-03907-w.

\section{Funding None.}

\section{Declarations}

Conflict of interest Maria Cristina Leonardi, Barbara Alicja JereczekFossa and Samantha Dicuonzo received a speaker honorarium from Accuray Inc. outside the current work. IEO received a research grant from Accuray Inc. entitled: "Data collection and analysis of Tomotherapy and CyberKnife breast clinical studies, breast physics studies and prostate study". Maria Alessia Zerella had a research fellowships from AIRC under IG 2019-ID. 23118 project "Phase I/II clinical trial on single fraction ablative preoperative radiation treatment for early-stage breast cancer". Mattia Zaffaroni received a research grant by the Eu- ropean Institute of Oncology-Cardiologic Center Monzino Foundation (FIEO-CCM), with a project entitled "Proton therapy vs photon-based IMRT for parotid gland tumors: a model based approach with Normal Tissue Complication Probability (NTCP)" outside the current study. The funders had no role in study design, data collection and analysis, decision to publish, or preparation of the manuscript. The remaining authors declare no conflicts of interest.

Ethics approval This study was performed in line with the principles of the Declaration of Helsinki.

\section{References}

AIRO Associazione Italiana di Radioterapia Oncologica (2013) La Radioterapia dei Tumori della Mammella Indicazioni e Criteri Guida

Bonzano E, Belgioia L, Polizzi G et al (2019) Simultaneous integrated boost in once-weekly hypofractionated radiotherapy for breast cancer in the elderly: preliminary evidence. In Vivo 33:19851992. https://doi.org/10.21873/invivo.11694

Brunt AM, Haviland JS, Sydenham M et al (2020) Ten-year results of FAST: a randomized controlled trial of 5-fraction whole-breast radiotherapy for early breast cancer. J Clin Oncol 38:3261-3272. https://doi.org/10.1200/JCO.19.02750

Ciammella P, Podgornii A, Galeandro M et al (2014) Toxicity and cosmetic outcome of hypofractionated whole-breast radiotherapy: predictive clinical and dosimetric factors. Radiat Oncol 9:97. https://doi.org/10.1186/1748-717X-9-97

Correa C, Harris EE, Leonardi MC et al (2017) Accelerated partial breast irradiation: executive summary for the update of an ASTRO evidence-based consensus statement. Pract Radiat Oncol 7:73-79. https://doi.org/10.1016/j.prro.2016.09.007

Diab SG, Elledge RM, Clark GM (2000) Tumor characteristics and clinical outcome of elderly women with breast cancer. J Natl Cancer Inst 92:550-556. https://doi.org/10.1093/jnci/92.7.550

Donato V, Valeriani M, Zurlo A (2003) Short course radiation therapy for elderly cancer patients. Evidences from the literature review. Crit Rev Oncol Hematol 45:305-311. https://doi.org/10.1016/ s1040-8428(02)00082-3

Dragun AE, Quillo AR, Riley EC et al (2013) A phase 2 trial of onceweekly hypofractionated breast irradiation: first report of acute toxicity, feasibility, and patient satisfaction. Int J Radiat Oncol Biol Phys 85:e123-128. https://doi.org/10.1016/j.ijrobp.2012.10. 021

Early Breast Cancer Trialists' Collaborative Group (EBCTCG), Darby S, McGale P et al (2011) Effect of radiotherapy after breast-conserving surgery on 10-year recurrence and 15-year breast cancer death: meta-analysis of individual patient data for 10,801 women in 17 randomised trials. Lancet 378:1707-1716. https://doi.org/ 10.1016/S0140-6736(11)61629-2

FAST Trialists group, Agrawal RK, Alhasso A et al (2011) First results of the randomised UK FAST Trial of radiotherapy hypofractionation for treatment of early breast cancer (CRUKE/04/015). Radiother Oncol 100:93-100. https://doi.org/10.1016/j.radonc.2011.06. 026

Freedman GM, Anderson PR, Li J et al (2006) Intensity modulated radiation therapy (IMRT) decreases acute skin toxicity for women receiving radiation for breast cancer. Am J Clin Oncol 29:66-70. https://doi.org/10.1097/01.coc.0000197661.09628.03

Goldsmith C, Haviland J, Tsang Y et al (2011) Large breast size as a risk factor for late adverse effects of breast radiotherapy: is residual dose inhomogeneity, despite 3D treatment planning and 
delivery, the main explanation? Radiother Oncol 100:236-240. https://doi.org/10.1016/j.radonc.2010.12.012

Harris JR, Levene MB, Svensson G, Hellman S (1979) Analysis of cosmetic results following primary radiation therapy for stages I and II carcinoma of the breast. Int J Radiat Oncol Biol Phys 5:257-261. https://doi.org/10.1016/0360-3016(79)90729-6

Hjermstad MJ, Fayers PM, Haugen DF et al (2011) Studies comparing Numerical Rating Scales, Verbal Rating Scales, and Visual Analogue Scales for assessment of pain intensity in adults: a systematic literature review. J Pain Symptom Manage 41:1073-1093. https://doi.org/10.1016/j.jpainsymman.2010.08.016

Ippolito E, Rinaldi CG, Silipigni S et al (2019) Hypofractionated radiotherapy with concomitant boost for breast cancer: a dose escalation study. BJR 92:20180169. https://doi.org/10.1259/bjr. 20180169

Kirova YM, Campana F, Savignoni A et al (2009) Breast-conserving treatment in the elderly: long-term results of adjuvant hypofractionated and normofractionated radiotherapy. Int J Radiat Oncol Biol Phys 75(1):76-81. https://doi.org/10.1016/j.ijrobp.2008.11. 005

Kraus-Tiefenbacher U, Sfintizky A, Welzel G et al (2012) Factors of influence on acute skin toxicity of breast cancer patients treated with standard three-dimensional conformal radiotherapy (3DCRT) after breast conserving surgery (BCS). Radiat Oncol 7:217. https://doi.org/10.1186/1748-717X-7-217

Kunkler IH, Williams LJ, Jack WJL et al (2015) Breast-conserving surgery with or without irradiation in women aged 65 years or older with early breast cancer (PRIME II): a randomised controlled trial. Lancet Oncol 16:266-273. https://doi.org/10.1016/ S1470-2045(14)71221-5

(1995) LENT SOMA scales for all anatomic sites. Int J Radiat Oncol Biol Phys 31:1049-1091. https://doi.org/10.1016/0360-3016(95) 90159-0

Linsell L, Burgess CC, Ramirez AJ (2008) Breast cancer awareness among older women. Br J Cancer 99:1221-1225. https://doi.org/ 10.1038/sj.bjc. 6604668

Maher M, Campana F, Mosseri V et al (1995) Breast cancer in elderly women: a retrospective analysis of combined treatment with tamoxifen and once-weekly irradiation. Int J Radiat Oncol Biol Phys 31(4):783-789. https://doi.org/10.1016/0360-3016(94) 00564-8

Murray Brunt A, Haviland JS, Wheatley DA et al (2020) Hypofractionated breast radiotherapy for 1 week versus 3 weeks (FAST-Forward): 5-year efficacy and late normal tissue effects results from a multicentre, non-inferiority, randomised, phase 3 trial. Lancet 395:1613-1626. https://doi.org/10.1016/S0140-6736(20)30932-6

Ortholan C, Hannoun-Lévi J-M, Ferrero J-M et al (2005) Long-term results of adjuvant hypofractionated radiotherapy for breast cancer in elderly patients. Int J Radiat Oncol Biol Phys 61:154-162. https://doi.org/10.1016/j.jirobp.2004.04.059

Owen JR, Ashton A, Bliss JM et al (2006) Effect of radiotherapy fraction size on tumour control in patients with early-stage breast cancer after local tumour excision: long-term results of a randomised trial. Lancet Oncol 7:467-471. https://doi.org/10.1016/ S1470-2045(06)70699-4

Pignol J-P, Olivotto I, Rakovitch E et al (2008) A multicenter randomized trial of breast intensity-modulated radiation therapy to reduce acute radiation dermatitis. J Clin Oncol 26:2085-2092. https://doi.org/10.1200/JCO.2007.15.2488

Reboucas LM, Campos CS, D'Amico GM et al (2019) Once-weekly hypofractionated radiotherapy for breast cancer: first results of a phase II clinical trial. Breast J 25:953-957. https://doi.org/10. 1111/tbj.13372

Rodin D, Tawk B, Mohamad O et al (2021) Hypofractionated radiotherapy in the real-world setting: an international ESTRO-GIRO survey. Radiother Oncol 157:32-39. https://doi.org/10.1016/j. radonc.2021.01.003

Rovea P, Fozza A, Franco P et al (2015) Once-weekly hypofractionated whole-breast radiotherapy after breast-conserving surgery in older patients: a potential alternative treatment schedule to daily 3-week hypofractionation. Clin Breast Cancer 15:270-276. https://doi. org/10.1016/j.clbc.2014.12.011

Sanz J, Zhao M, Rodríguez N et al (2018) Once-weekly hypofractionated radiotherapy for breast cancer in elderly patients: efficacy and tolerance in 486 patients. Biomed Res Int 2018:8321871. https:// doi.org/10.1155/2018/8321871

Smith BD, Bentzen SM, Correa CR et al (2011) Fractionation for whole breast irradiation: an American Society for Radiation Oncology (ASTRO) evidence-based guideline. Int J Radiat Oncol Biol Phys 81:59-68. https://doi.org/10.1016/j.ijrobp.2010.04.042

START Trialists' Group, Bentzen SM, Agrawal RK et al (2008) The UK Standardisation of Breast Radiotherapy (START) Trial B of radiotherapy hypofractionation for treatment of early breast cancer: a randomised trial. Lancet 371:1098-1107. https://doi.org/10. 1016/S0140-6736(08)60348-7

Truong PT, Bernstein V, Lesperance M et al (2006) Radiotherapy omission after breast-conserving surgery is associated with reduced breast cancer-specific survival in elderly women with breast cancer. Am J Surg 191:749-755. https://doi.org/10.1016/j.amjsurg. 2005.07.028

Whelan TJ, Pignol J-P, Levine MN et al (2010) Long-term results of hypofractionated radiation therapy for breast cancer. N Engl J Med 362:513-520. https://doi.org/10.1056/NEJMoa0906260

Wildiers H, Kunkler I, Biganzoli L et al (2007) Management of breast cancer in elderly individuals: recommendations of the International Society of Geriatric Oncology. Lancet Oncol 8:1101-1115. https://doi.org/10.1016/S1470-2045(07)70378-9

Publisher's Note Springer Nature remains neutral with regard to jurisdictional claims in published maps and institutional affiliations. 